\title{
Evaluation of the educational impact of a special study module on maritime medicine for medical undergraduate students
}

\author{
Nora McCarthy ${ }^{1}$, Siun 0'Flynn ${ }^{1}$, John Murphy ${ }^{2}$, David Barry ${ }^{3}$, Maria Luisa Canals ${ }^{4}$ \\ ${ }^{1}$ College of Medicine and Health, University College Cork, Cork, Ireland \\ ${ }^{2}$ Irish Naval Service, Ireland \\ ${ }^{3}$ Irish Naval Service, National Maritime College of Ireland, Ireland \\ ${ }^{4}$ Maritime Health ISM, Tarragona, Spain
}

\begin{abstract}
Background: The hazardous occupation of seafaring brings many unique medical challenges. Despite its international nature, maritime medicine does not typically form a part of undergraduate medical studies. A unique and innovative, optional student-selected module (SSM) 'maritime medicine' was offered to medical students. A key objective was to develop students' attitudes to maritime medicine and increase their awareness of the discipline and its specialised nature.

Aim: The aim of this study was to assess qualitatively and quantitatively the educational impact of the maritime medicine SSM and to improve the module content and design for future academic years.

Materials and methods: Students' perceived relevance and knowledge before and after the module was assessed using a Likert-based questionnaire. Comparison was made with controls in the post module 100 multiple choice question (MCQ) paper. Qualitative feedback was obtained from semi-structured focus student discussion groups and the questionnaire's free comments section.

Results: A significant increase in perceived knowledge was seen between pre and post module $p<3.45 \times 10^{-10}$, matched with the module students performing significantly better than controls in the end-of-module MCQ paper $\left(p<8.99 \times 10^{-20}\right)$. Qualitative analysis revealed 5 main themes: teaching methods, appreciation of non-academic instructors, appreciation of maritime medicine unique requirements, timetabling and enjoyment. Conclusions: This unique and innovative maritime medicine module harnessed local expertise and raised the awareness and profile of maritime medicine among undergraduate medical students. It was very well received and had a significant educational impact. Practical teaching methods were highly valued by students, with these areas also performing best in quantitative analysis.
\end{abstract}

(Int Marit Health 2013; 64, 4: 195-201)

Key words: maritime medicine, undergraduate education, medical training, special study module, teaching methods

\section{INTRODUCTION}

Seafaring is a unique and dangerous occupation, with recent studies showing higher fatality rates among seafarers compared to other occupations [1, 2]. It is also one of the most isolated professions with limited access to medical care possible at sea [3]. However, the discipline of maritime medicine is poorly defined in medical world.
It has been described as "any medical activity related to questions concerning the employment, working conditions, living conditions, health and safety of workers at sea" [4]. This broad definition covers all the medical-related issues, both before and during the employment, for the vast range of seafarers and also those working on offshore installations and divers. This broad sphere includes occupational medi- 
cine, tropical medicine, and emergency medicine. Doctors exposed to maritime-related problems can be overwhelmed due to ignorance of specific conditions and regulations in the maritime industry. International postgraduate medical training courses in maritime occupational health exist, but the requirement for this training varies from country to country [5]. Such courses are often organised only locally, with different courses having different content with no standardisation. The progress has been made in recent times, with a masters degree through the University of Cadiz, available in English and Spanish, and a diploma through University of Brest, available in French only. In Poland, maritime and tropical medicine is taught at a postgraduate level with the introduction of obligatory sessions for final medical students on topics of maritime medicine, including hyperbaric medicine [6]. Maritime medicine is a truly international field, yet typically it does not form a part of the undergraduate medical studies. The exposure of medical students to the field of maritime medicine has not been explored to date. University College Cork (UCC) has 2 undergraduate medicine courses, a 5-year school leaver direct entry course and a 4-year graduate entry one. UCC offers special study modules to both sets of medical students, allowing them the opportunity to focus on specific areas of interest.

The reason for the introduction of this and other student-selected components is the General Medical Council "Tomorrow's Doctors" document, which advocates allocating up to $25 \%$ of course time to such initiatives [7]. This represents revolutionary change in the education of undergraduate medical students in Ireland. Special study modules challenge the traditional style of teaching and encourage more student-centred learning. They present students with the opportunity to go beyond the core curriculum by studying areas of specific interest to them in greater depth [8]. Another key role of special study modules is to encourage self-directed learning by developing the attitudes and skills necessary for the future lifelong learning. Special study modules are "no less important than the core curriculum, but they focus not on the immediate requirements of the pre-registration year, but on the long-term intellectual and attitudinal demands of a professional life, that will constantly be challenged by growth of knowledge and change of circumstance' [7]. The variety of modules offered depends on the resources, interest and enthusiasm of available staff.

With substantial co-operation from the Irish Naval Service (INS), the Irish Coast Guard (IRCG), and the National Maritime College of Ireland (NMCl), UCC introduced a maritime medicine module worth 5 credits to $3^{\text {rd }}$-year direct entry and $2^{\text {nd }}$-year graduate entry students. This is one of the very few maritime medicine modules in existence at the undergraduate level. Cork is Ireland's maritime capital and hosts the $\mathrm{NMCl}$, the INS and Medico Cork, Ireland's
Telemedical Maritime Assistance Services (TMAS's). NMCI is a purpose-built 3rd level college facility offering naval service and merchant marine degree courses. Students undergoing the maritime medicine special study module were exposed to a variety of aspects of maritime medicine over a 14 week period of 2 hourly sessions. The module content was chosen by the author, with delivery being undertaken by medical educators and specialists in the various topics chosen. Individual experts with such diverse backgrounds as Surgeon Admiral Frank Golden RN (Retd) and Frank Lynch Cdre NS (Retd) have also lectured on the course. The module involved a mixture of theoretical and practical sessions with approval being obtained from the College of Medicine and Health Teaching and Curriculum Committee. A maritime historical background including various conventions of the sea and their origins was discussed. An awareness of the medical training of the various categories of seafarers and the medical equipment carried by different vessels was instilled into the students. The concept of telemedicine was introduced, first by theory and then practically in a session on radio communications. The role of telemedical assistance services and, in Ireland's case, Medico Cork was introduced. Cruise ship medicine was also discussed. The effects of cold and water environments on physiology and function, including the management of hypothermia and drowning were then covered. Occupational maritime medicine was emphasised, with numerous real case scenarios being presented to the students to discuss. Diving medicine was also discussed, both theoretically and practically through the observation of the use of the INS diving chamber. The very important element of the psychological and psychiatric issues that may be faced by seafarers was discussed. Dealing with a major emergency at sea also played a part in this special study module.

Practical sessions included a full day mastering radio communications, with exercises on the use of telemedicine at sea. Each student also received a Personal Survival Techniques (PST) STCW-95 certificate. This 1-day course took place under the instruction of the Irish Navy in the NMCl. Here, the sea survival pool can simulate conditions at sea from wind and rain to thunder and lightning and waves. The Irish Coast Guard gave the students a flavour of what it is like to work in extremely challenging conditions, as well as general information, such as the carried equipment. The students undertook a flight in the IRCG Sikorsky helicopter to experience firsthand the difficulties of delivering medical care in the hostile environment of a moving helicopter. Finally, the students' first aid skills were challenged in the confines of a naval vessel, where actors simulating various injuries had to be stabilised and made ready for the helicopter evacuation (Table 1). A visit to a local Royal National Lifeboat Institution base reminded the students of the important role voluntary services play in the event of emergencies at sea. 
Table 1. Table on course content

\begin{tabular}{ll}
\hline Topic & Teaching method \\
\hline History, rules and regulations & Lecture \\
Telemedicine & Lecture and practical \\
Occupational maritime medicine & Case-based discussions and presentation \\
Fundamentals of diving physiology & Lecture and practical \\
The sea and psychiatry & Lecture \\
Radio communications & Lecture and practical \\
Near-drowning & Lecture \\
Major emergency management & Lecture \\
Cold injuries and hypothermia & Lecture \\
Personal survival training & Lecture and practical \\
Role of Coast Guard & Lecture and practical \\
Role of voluntary services in maritime emergencies & Lecture and practical \\
First aid exercise on Irish naval vessel & Lecture and practical
\end{tabular}

A key objective of the student-selected module (SSM) was to develop students' attitudes to maritime medicine and increase their awareness of the discipline and its specialised nature. Other objectives included improving the students' knowledge and skills in areas such as communication skills, and allowing exploration of relevant aspects of physiology.

Formal assessment of the students was in the form of a multiple choice question (MCQ) paper with 100 questions. No negative marking was employed.

The aim of the study was to assess, both qualitatively and quantitatively, the educational impact of the maritime medicine module in medical education and to improve the module content and design for future academic years.

\section{PARTICIPANTS}

The maritime medicine special study module was set up in 2010 to run over 1 semester. It included a combination of methodologies (didactic, practical incl. simulation). Medical students in their $3^{\text {rd }}$ year combined with graduate entry year 2 were invited to select a special study module to study. The annual module capacity was 20 students, with interest received from at least twice that number each year. Places were offered on a first come, first served basis with no special entry criteria existing.

\section{MATERIALS AND METHODS}

\section{ETHICS AND CONFIDENTIALITY}

Ethic approval was granted by the Cork Hospitals Research Ethics Committee. Written informed consent was obtained from the students. Detailed explanation of the questionnaire was presented to the students prior to its use, with the assurance given of confidentiality of results.
Data was subsequently anonymously stored on a password-protected computer.

\section{ASSESSMENT}

To evaluate the effectiveness of the module, the students were asked to fill in a Likert-based questionnaire both before and on completion of the module. This was first piloted among the experts in maritime medicine and medical education, and amended accordingly. The questionnaire looked at their perceived relevance and knowledge both before and after the module, with a score of 1 meaning absolutely no relevance or perceived knowledge and 5 meaning extremely relevant or great level of perceived knowledge. Comparison was made with a control group's results in the post module assessment MCQ. The Likert-based questionnaire also included a free comments section, where the students were encouraged to comment on the teaching sessions and on the course in general. Qualitative feedback was also obtained from semi-structured focus student discussion groups.

\section{DATA ANALYSIS}

Quantitative and qualitative assessment of the module was undertaken. Paired t-test was used to analyse the changes in perceived knowledge and relevance pre and post module. A single tail type $3 \mathrm{t}$-test was used in the quantitative analysis of differences in MCQ results between test and control group, as the prediction was that the test group would have a higher score than the control group, and the results were from different people and thus not paired, with a significance level $p<0.05$. After transcription and immersion in the material, qualitative information was independently analysed, followed by coding and categorisation of the data. 


\section{RESULTS}

\section{QUALITATIVE}

Qualitative analysis revealed 5 main themes: teaching methods (theoretical vs. practical), appreciation of non-academic instructors, appreciation of maritime medicine's unique requirements, timetabling and enjoyment.

\section{Teaching methods}

The majority of the students greatly appreciated and preferred the practical aspects of the course. The following section is a transcript of some of the student comments, with $\mathrm{S} 1$ being student 1 , S2 - student 2 etc.

- Practical sessions were more involving, forcing the students to think and interact; extremely enjoyable method of learning and realising the difficulties of maritime medicine - Student 3 (S3)

- Practical session gave us invaluable insight into the situations faced at sea, whereas facts/numbers can fade - S14

- There is a place for both theory and practical sessions, but the practical sessions were much more enjoyable; they were all new experiences, we sat in a lecture room every day! - S19

- It was easier to remember the information after the practical sessions - S6

- I found the practical sessions to be an excellent and enjoyable way to learn - S8

- It is difficult to appreciate the true nature of maritime medicine without seeing the practical side - S13

- Practical elements were the highlight of the course - PST, IRCG, Navy; practical sessions provide more learning - S17

- The course was a nice balance of theory vs. practical -S7

- Practical sessions were much more interactive, easier to concentrate and pay attention, felt more open to ask questions - S15

\section{Appreciation of non-academic instructors}

- Working with people in the field, not lecturers or medical practitioners was very educational - S12

- The course was great, as took us to the real maritime situations and work with real mariners - S5

- Relaxed atmosphere, instructors highly skilled and genuinely interested, leaving a positive experience - S16

\section{Appreciation of maritime medicine unique requirements}

- The practical aspect is required, as it is impossible to appreciate maritime medicine issues without experiencing the conditions and challenges - S2
- I have a better appreciation of how difficult it is to provide care at sea and also how dangerous environment the ocean is $-\mathrm{S} 7$

- I can now better appreciate the difficulties faced by seafarers in a medical emergency; I appreciate the huge numbers and effort involved in maritime medicine - S8

- I enjoyed learning about aspects of medicine that might not be considered mainstream - S9

- The theory is really interesting and completely different to anything else we have studied in medicine - S15

- The knowledge base is fascinating and strangely not something often covered - S16

\section{Enjoyment}

- It was amazing, so much fun while learning so much at the same time $-\mathrm{S} 13$

- I enjoyed the course, it was fun - S14

- It was an extremely enjoyable method of learning - S17

\section{Timetabling issues}

- I felt the course should be re-ordered - practical first'; I am also busy close to the exams - S3

- I would have enjoyed it a lot more had my work load with other things been less - S12

- Try to make practical sessions earlier in the year as they are too close to the exam time - S19

- Do the practical sessions earlier in the year when I could enjoy them without the exam stress - S6

- Do the practical sessions earlier in the year -S7

\section{QUANTITATIVE}

Twenty students were enrolled in the module in each of the 2 analysed academic years, making a total of 40 involved. All the students were invited to participate in the evaluation. Of these, 36 successfully completed the pre and post questionnaire. Nineteen of these were women and 17 were men, with 20 students being direct entry and 16 being graduate entry students. Six had no prior maritime experience, with the rest having various levels of exposure to the sea, ranging from leisure surfers, divers and sailors, to diving instructors and 1 marine biologist and former member of the US Navy.

The increase in perceived relevance was graphed against the increase in perceived knowledge. The maximum potential attainable score per question in each of these categories in the questionnaire was 170. Changes in perceived relevance and knowledge were analysed for both the theory and practical elements of the course (Figs. 1-3). The control and actual students' performance on the MCQ was analysed.

The majority of the students showed close to the same change in knowledge and relevance after the course com- 


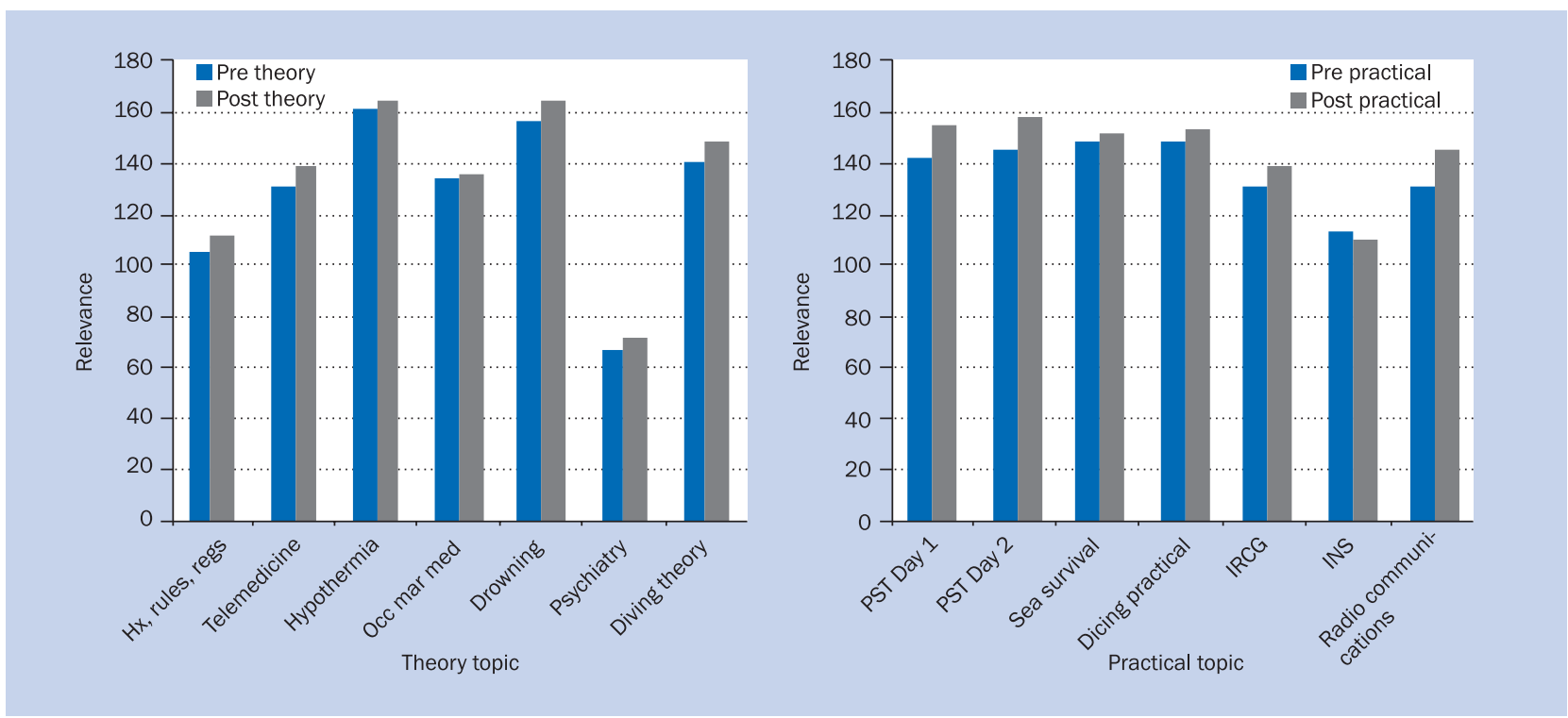

Figure 1. Changes in perceived relevance pre and post module; Hx - history; regs - regulations; Occ mar med - occupational maritime medicine; PST - Personal Survival Techniques; IRCG - Irish Coast Guard; INS - Irish Naval Service

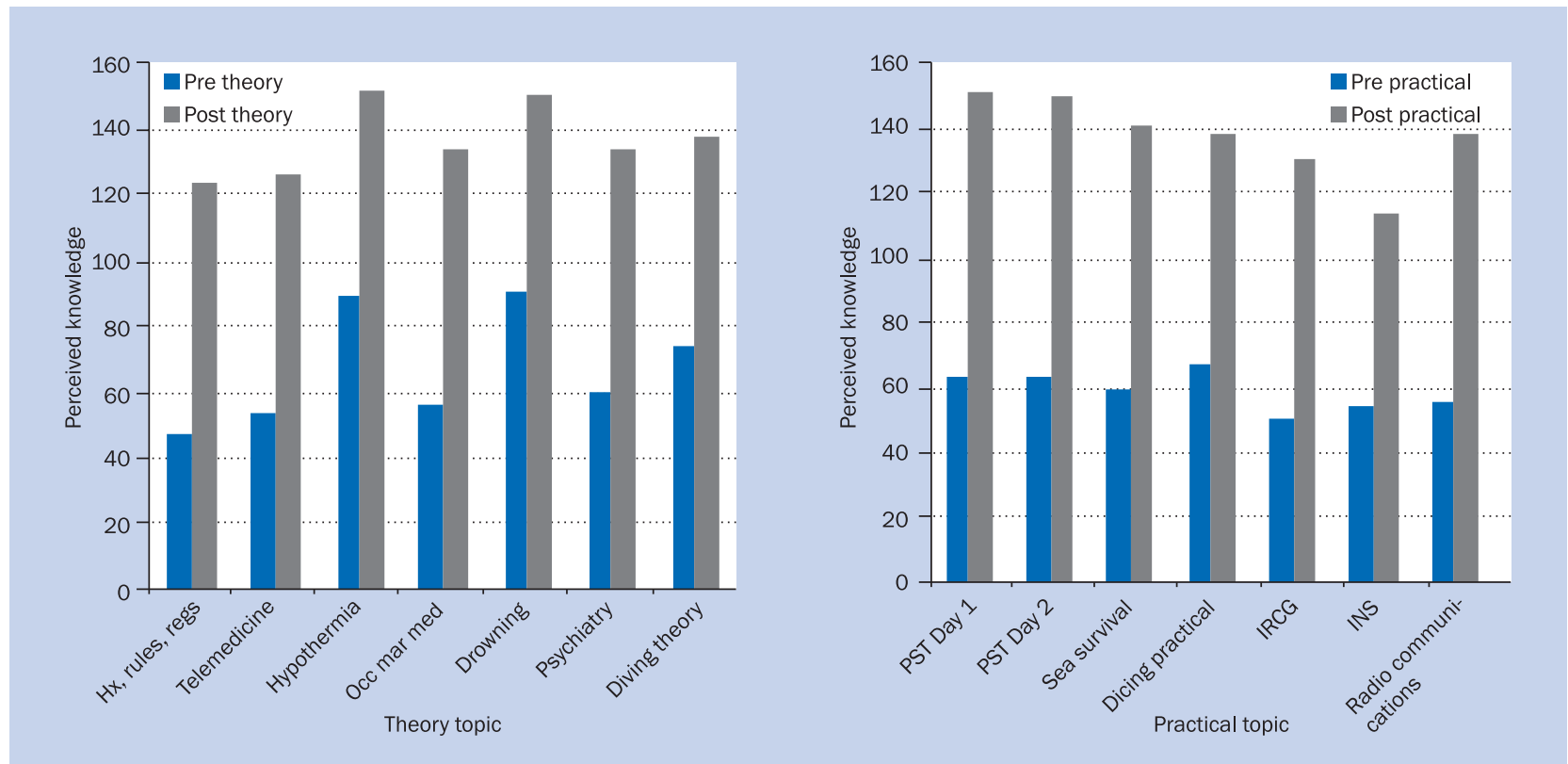

Figure 2. Changes in perceived knowledge pre and post module; abbreviations as in Figure 1

pletion, with a few exceptions that will be discussed later. A maximum of $5 \%$ change in relevance in both the theory and practical elements was noted in the post-module evaluation compared to the pre-module, with all elements scoring high as relevant. This contrasts sharply with the increase in perceived knowledge overall $\left(p<2.76 \times 10^{-11}\right)$, with an increase of $51 \%$ in perceived knowledge in the theory aspects, and $57 \%$ in the practical-based parts of the module, both of which are highly statistically significant $\left(p<1.51 \times 10^{-7}\right.$, $p<3.7 \times 10^{-7}$, respectively).
This increase in perceived knowledge was matched by the actual module (test)students performing substantially better than the controls in the end-of-module 100 question multiple choice paper (Table 2). Due to no negative marking, $50 \%$ is what is expected based on the random choice. The control group had a mean of $51.83 \%$ with a standard deviation of 8.95. The actual module students had a mean of $82.95 \%$ with a standard deviation of 4.84 . This difference is highly statistically significant $\left(p<8.99 \times 10^{-20}\right.$ overall, $p<2.09 \times 10^{-09}$ for theory aspects, $p<4.58 \times 10^{-12}$ for practical elements). 


\section{DISCUSSION}

Mixed methods research in medicine has been shown to potentially offer benefits over either qualitative or quantitative analysis used independently [9, 10]. Qualitative analysis of the maritime medicine special study module revealed 5 main themes: teaching methods (theoretical vs. practical), appreciation of non-academic instructors, appreciation of the unique requirements of maritime medicine, timetabling and enjoyment.

Learning, to be effective, must involve constructive mental activity. Effective curriculum development requires moving away from didactic teaching methods towards a practical and experiential learning pathway, where emphasis is placed on knowing how rather than knowing all $[11,12]$. This in turn can lead to improved communication and teamwork skills [13].

Each teaching method has its own advantages and disadvantages, with no single best way of teaching and learning. However, this study does suggest that a mixture of both practical-and theoretical-based teaching gives the best recipe for the effective learning. Lectures provide valuable overview and efficiency, but can involve little participation from the students. Reinforcing the theoretical with practical

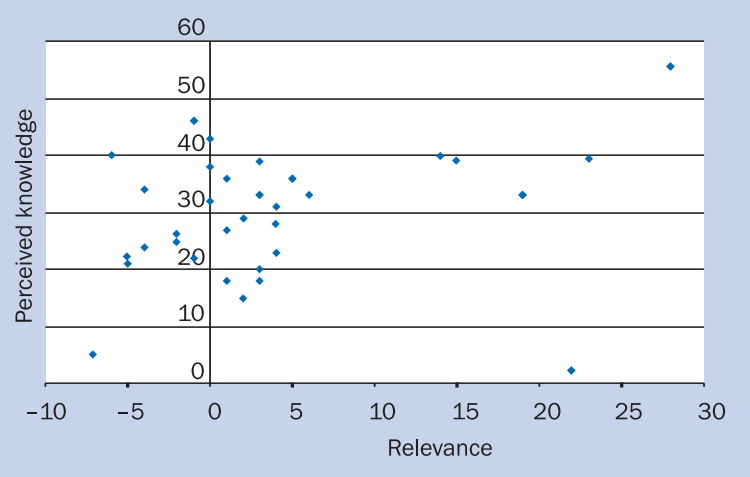

Figure 3. Change in perceived knowledge element encourages students to take charge of their own learning and also to develop the skills of working in a group.

A cause for concern that was highlighted was the timetabling involved. This can often lead to anxiety based on perceived differences in workload, which is not necessarily valid. Students may potentially confuse "work load" with "contact time" [14]. As the exams are such an important part of students' lives, anxiety was raised about spending time off the campus close to the main subject examination times. According to the General Medical Council, it is important that future doctors develop strategies for coping with the uncertainties and differences between different SSM programmes [7].

The special study modules in general have been found to be stimulating, highly rated and novel learning opportunities $[15,16]$.

Student feedback in this maritime medicine module clearly demonstrated the benefits perceived from the module in both a personal and professional viewpoint, the majority stating they would recommend it to other students. It allowed exploration of relevant aspects of physiology while developing management and handover skills required to deal with clinical presentation in challenging settings. It demonstrated successful collaboration and sharing of resources between UCC, NMCI, IRCG, INS and was very well received by the participating students.

The majority of students showed the same change in knowledge and relevance after the course completion, with a few exceptions. One student showed a low increase in perceived knowledge. On the review this student was a marine biologist and former member of the US navy, so this low increase in perceived knowledge is not surprising with such a background. Of the outliers on the other side - a huge increase in relevance and perceived knowledge pre and post course -1 had no previous maritime exposure and 2 expressed a strong desire to join the navy as doctors. No obvious discerning features were noted for the other 2 outliers.

Table 2. Comparison of control and test multiple choice question (MCQ) paper results ( $1=100 \%$ )

\begin{tabular}{lllllll}
\hline MCQ per topic & $\begin{array}{l}\text { Control } \\
\text { mean }\end{array}$ & $\begin{array}{l}\text { Control } \\
\text { SD }\end{array}$ & $\begin{array}{l}\text { Test } \\
\text { mean }\end{array}$ & $\begin{array}{l}\text { Test } \\
\text { SD }\end{array}$ & $\begin{array}{l}\text { Mean difference } \\
\text { (95\% confidence interval) }\end{array}$ & $\begin{array}{l}\text { P value single tail } \\
\text { type 3 t-test }\end{array}$ \\
\hline History, rules, regulations & 0.45 & 0.20 & 0.86 & 0.20 & $-0.41(-0.48$ to -0.34$)$ & 0.0001 \\
Cold injuries and hypothermia & 0.56 & 0.21 & 0.78 & 0.30 & $-0.22(-0.33$ to -0.11$)$ & 0.023 \\
Occupational maritime medicine & 0.56 & 0.21 & 0.67 & 0.20 & $-0.11(-0.20$ to -0.02$)$ & 0.123 \\
Near drowning & 0.72 & 0.17 & 0.91 & 0.10 & $-0.19(-0.26$ to -0.12$)$ & 0.006 \\
Personal survival training & 0.52 & 0.27 & 0.88 & 0.20 & $-0.36(-0.46$ to -0.25$)$ & $5.32 \times 10^{-7}$ \\
Diving & 0.50 & 0.24 & 0.86 & 0.20 & $-0.36(-0.45$ to -0.26$)$ & $2.88 \times 10^{-5}$ \\
Radio communications & 0.39 & 0.24 & 0.63 & 0.30 & $-0.23(-0.37$ to -0.09$)$ & 0.046 \\
Emergency management & 0.48 & 0.22 & 0.84 & 0.10 & $-0.36(-0.45$ to -0.28$)$ & 0.0002 \\
Irish Coast Guard & 0.54 & 0.17 & 0.93 & 0.10 & $-0.39(-0.45$ to -0.32$)$ & 0.002
\end{tabular}


The 2 areas that displayed the greatest perceived knowledge pre module were drowning and cold injuries and hypothermia. This would be expected based on this group's pre-existing physiology and pathology knowledge. Even here it was felt that the knowledge in these areas had increased by a factor of 1.64 and 1.69 respectively on completion of the course.

All lectures, except occupational maritime medicine, showed a statistically significant difference between the control and test group MCQ answers. Comparing control and test MCQ results over each aspect of the module, 4 of the 5 areas that showed the biggest change in results were very much maritime based, with practical exposure playing a major role in 3 of these areas, namely diving, IRCG and Sea Survival. This tied in with the qualitative results, which highlighted that practical was the preferred method of teaching on this module. Interestingly, a purely theoretical part of the course - history, rules and regulations - showed an increase in scoring of $41 \%$ compared to controls. Controls would have had absolutely no knowledge of this area from any previous study they might have done.

The lowest increase in MCQ results was noted in occupational maritime medicine and drowning lectures. The control group performed well on drowning related questions (mean $72 \%$ ), which is not surprising given that physiology and pathology are taught in this academic year also.

Occupational maritime medicine showed one of the highest increases in perceived knowledge by a factor of 2.35 , with the lecture being mentioned on numerous occasions in the qualitative aspect as "very interesting, informative, unaware that would be so complex, great interactive teaching style". However, this perceived increase in knowledge was not matched by a good performance in the MCQ paper. The control group scored a mean of $52 \%$ in the occupational maritime section of the MCQ, which is to be expected based on random choice. The actual module students scored a mean of $67 \%$, the lowest of all the areas of the MCQ. Questions on this topic were very much based on rules and regulations specific to occupational maritime medicine, all of which would have been a new and complex area for the students.

Limitations include the small number of students involved. They were also a self-selected group of students who may have had a positive bias towards the field of maritime medicine and thus the findings may not be generalisable to the general student population.

The author would encourage other institutions to consider offering optional modules in maritime medicine to allow students the opportunity to explore the field further and to raise the profile of maritime medicine education.

\section{CONCLUSIONS}

This unique and innovative maritime medicine module harnessed local expertise and raised the awareness and profile of maritime medicine among undergraduate medical students. It was very well received by medical students and had a significant educational impact in terms of changing students' perceived and actual knowledge in maritime medicine. Practical elements of teaching were shown to be highly valued by students with these areas also performing best in the quantitative analysis.

\section{ACKNOWLEDGEMENTS}

The author would like to thank the students of MX3001, who contributed substantially with their valuable feedback, and the professionals who continue to support this module with their time and expertise.

\section{REFERENCES}

1. Roberts SE. Fatal work-related accidents in UK merchant shipping from 1919 to 2005. Occup Med 2008; 58: 129-137.

2. Rodriguez JL, Formoso JAF. Work-related accidents in the maritime transport sector. J Navigation 2007; 60: 303-313.

3. Oldenburg M, Baur X, Schlaich C. Occupational risks and challenges of seafaring. J Occup Health 2010; 52: 249-256.

4. Carter T, Schreiner A. Preface. In: Textbook of maritime medicine. $2^{\text {nd }}$ Ed. 2013 [cited 2013 Jan 3]. Available from: http://textbook.ncmm.no/.

5. Dewitte JD. Health problems - education. In: Textbook of maritime medicine. $2^{\text {nd }}$ Ed. 2013 [cited 2013 Jan 3]. Available from: http:// textbook.ncmm.no/.

6. Chodnik T, Jeżewska M, Jaremin B, Kotłowski A, Leszczyńska I, Grubman-Nowak M. Polish system of education in maritime health care and medical assistance for seafarers. Int Marit Health 2013; 64: 24-29.

7. General Medical Council [Internet; cited 2013 Feb 22]. Available from: http://www.gmc-uk.org/education/undergraduate/tomorrows_doctors_2009.asp.

8. Sweeney C, Lynch G, Khashan A, Maher B, Murphy M, O'Brien T. The impact of a medical undergraduate student-selected module in palliative care. BMJ Support Palliat Care DOI: 10.1136/bmjspcare-2012-000283.

9. Durning SJ, Elnicki ME, Gruppen L, Torre D, Hemmer PA. 2010. AMEE spotlight: AMEE 2009 spotlight on educational research. Med Teach 2009; 32: 340-342.

10. Johnson RB, Onwuegbuzie AJ. Mixed methods research: a research paradigm whose time has come. Educ Res 2004; 33: 14-26.

11. Morgan PJ, Cleave-Hogg D, Desousa S, Lam-McCullough J. Applying theory to practice in undergraduate education using high fidelity simulation. Med Teach [Internet; cited 2013 Feb 20]; 2006; 28 (1): e10-e15. Available from http://www.ncbi.nlm.nih.gov/pubmed/16627314.

12. Steinert $\mathrm{Y}$, Mann K, Centeno A et al. A systematic review of faculty development initiatives designed to improve teaching effectiveness in medical education: BEME guide no. 8. Med Teach 2006; 28: 1-30.

13. Jones R, Higgs R, De Angelis C, Prideaux D. Changing face of medical curricula, Lancet 2001; 357: 699-703.

14. Yates MS, Drewery S, Murdoch-Eaton DG. Alternative learning environments: what do they contribute to professional development of medical students? Medical Teach 2006; 24: 609-615.

15. Byrne PA, Lewis SE, Thompson W. Special study modules: a student's perspective. Medical Teach 1999; 21: 299-301.

16. Jha V, Duffy S, Murdoch-Eaton D. Development of transferable skill during short special study modules: students' self-appraisal. Med Teach 2002; 24: 202-207. 